\title{
Route Design Model of Feeder Bus Service for Urban Rail Transit Stations
}

\author{
Zhenjun Zhu, ${ }^{1}$ Xiucheng Guo, ${ }^{1}$ Jun Zeng, ${ }^{1}$ and Shengrui Zhang ${ }^{2}$ \\ ${ }^{1}$ School of Transportation, Southeast University, Si Pai Lou No. 2, Nanjing 210096, China \\ ${ }^{2}$ School of Highway, Chang'an University, South Second Ring Road, Xian 710064, China \\ Correspondence should be addressed to Xiucheng Guo; seuguo@163.com
}

Received 27 May 2016; Revised 2 December 2016; Accepted 6 December 2016; Published 16 January 2017

Academic Editor: Jesus M. Fernandez Oro

Copyright (C) 2017 Zhenjun Zhu et al. This is an open access article distributed under the Creative Commons Attribution License, which permits unrestricted use, distribution, and reproduction in any medium, provided the original work is properly cited.

\begin{abstract}
As an important part of urban public transportation systems, the feeder bus fills a service gap left by rail transit, effectively extending the range of rail transit's service and solving the problem of short-distance travel and interchanges. By defining the potential demand of feeder bus services and considering its relationship with the traffic demands of corresponding staging areas, the distance between road and rail transit, and the repetition factor of road bus lines, this paper established a potential demand model of roads by opening feeder bus services and applying a logit model for passenger flow distribution. Based on a circular route model, a route starting and ending at urban rail transit stations was generated, and a genetic algorithm was then applied to solve it. The Wei-Fang community of Shanghai was selected as the test area. Per the model and algorithm, the feeder route length was conformed to a functional orientation of short-distance travel and the feeder service of a feeder bus; the route mostly covered where conventional bus lines were fewer, which is a finding that is in agreement with the actual situation; the feasibility of the model and algorithm was verified.
\end{abstract}

\section{Introduction}

In recent years, domestic cities have placed stress on large and medium capacity public transportation; we already have rail transit, light rail, trams, and bus rapid transit, among others. However, small capacity public transportation around the community is so minimal that it obviously cannot meet the travel demand of residents. The relatively late development of rail transit, alternative transportation modes, unreasonable connectivity relations, and the totally enclosed rail transit operation environment resulted in the smaller service scope of rail transit. Feeder bus services could fill gaps left by rail transit, could enhance the competency in order to attract traffic, and could improve travel convenience and accessibility for the elderly and other vulnerable groups. Therefore, in the background of the accelerated expansion of the urban rail transit network, research on a feeder route between a feeder bus and rail transit could further develop large capacity advantages, including fast speed and high reliability of rail transit; these advantages are of great significance for building a balanced, convenient, and multilevel urban public transport system.
A feeder bus was originally proposed by real estate developers and property management companies; it drives back and forth between communities and central downtown on a fixed route. Then, it gradually evolves into feeder bus services to improve the urban passenger transportation system [1]. At present, there is no specific or unified definition for a feeder bus. It is also called a community bus, shuttle bus, microcirculation bus, last kilometer bus, and public light bus. In this paper, the term feeder bus refers to small public transport vehicles approximately $7 \mathrm{~m}$ in size that provide short-distance travel to feeder rail transit stations. Feeder buses are an important part of urban public transport operation modes that provide a feeder service for large and medium capacity public transportation.

\section{Literature Review}

Early bus route selection and passenger flow assignment methods were proposed by Dial and Le Clercq; they applied a heuristic algorithm to calculate the shortest path in a network $[2,3]$. Chriqui and Robillard selected a subset of lines from a 
set of alternate routes based on the characteristics of passenger choice behavior [4]. Nguyen and Pallottino introduced a super road map to study selection strategies of alternative lines set at bus stations [5]. Hickman and Bernstein gave a path selection method describing how the order was determined [6]. Kurauchi et al. discussed the application of the Markov method in the path selection process of a stochastic and deterministic user equilibrium model [7]. Kuah and Perl proposed an optimization method for designing a unified shuttle-rail system and determined the path of each line based on fleet size [8]. Chang and Schonfeld set up shuttle alignments based on a simple rectangular area and proposed that the many-to-one demand mode was more flexible [9]. Chien and Schonfeld established a mathematical model to make a railway line transfer to feeder bus lines more convenient [10]. Chien et al. considered constraints of geography, passenger flow, budget, and others and then proposed a method of operating feeder bus services based on transfer centers under a grid-like road network [11-13]. Ceder proposed a potential demand indicator for shuttle buses and established a model based on maximization of the indicator $[14,15]$. Fan and Machemehl analyzed potential characteristics of bus route optimization under the condition of variable demand and then proposed a nonlinear mixed integer programming model based on multiple objectives [16]. O'Sullivan et al. assumed that a feeder bus could be parked where passenger demand existed and constructed an optimization model of multiple feeder bus lines based on GIS [17]. Kuan et al. proposed to use heuristics, a genetic algorithm, and ant colony algorithms, to solve the feeder bus network design problem [18]. Chang and Yu proposed a mathematical model to maximize the business and social welfare and obtained the optimal route design in a given rectangular study area [19]. Shrivastav and Dhingra constructed a mathematical model of feeder buses combined with railway stations, with the goal of minimizing route travel time the model was solved by heuristic algorithms [20]. Szeto and Wu optimized several feeder bus lines combined with transfer hubs within the objective function of passenger travel cost and proposed using heuristic algorithms for station sequence optimization [21]. Xiong et al. constructed a model of feeder bus route design optimization considering total cost under the half-reality road network and obtained the optimal stations using heuristics algorithms [22]. Lin and Wong present a feeder bus route design model, capable of minimizing route length and travel time and maximizing service coverage for trip generation; a multiobjective programming approach is developed to solve the model [23].

Many researchers have made efforts to optimize bus routes, but they mainly concentrated on mathematical models; consideration of actual road networks, study areas, and relationships with conventional bus line coverage is minimal. Therefore, combined with the existing studies and investigations, we find that a circular route could maximize the flexible advantage of a feeder bus, under the condition of shorter length for feeder bus lines. Accordingly, this paper adopts a circular route model to study the optimal route. The major objective of the research is to develop a model for feeder routes to maximize potential demand. Based on the actual road network, this paper defines the potential demand that links open feeder bus services and introduces the potential demand reduction coefficient to reflect the relationship between the operating conventional bus lines and feeder bus lines. As a case study, the Wei-Fang community area of Shanghai is selected to verify the validity of the model.

\section{Mathematical Model}

3.1. Study Area. Studies have found that the arrangement of 6- to 8-kilometer-long bus lines surrounding urban rail transit stations could not only meet transfer demand but also promote transfer passengers who are traveling by walking, nonmotor vehicles, or taxis to move onto public transportation modes [24]. Under the condition of shorter length for feeder bus lines, a circular route could maximize the flexible advantage of a feeder bus, expanding the scope of service and attracting more passenger flow through an appropriate bypass. Per the survey of feeder bus services in Shanghai, a feeder bus that feeds rail transit is mainly serving large residential communities or relatively concentrated residential areas enclosed by an urban road network that is located on one side of rail transit lines. Therefore, this paper studies the optimal route for a feeder bus to feeder rail transit stations under the circumstances of single-circulation feeder mode.

3.2. Model Construction. This paper studies urban road links and defines the potential demand that links open feeder bus lines. The potential demand of a link is proportional to the traffic demand of the corresponding aggregated area and the distance between the link and a rail transit station. The farther that a link is away from rail transit stations, the greater the demand is for traveling by feeder bus. The potential demand of a link is inversely proportional to the average distance of passengers to be attracted to that link. The more regular bus lines that are operating in the link, the less demand is for traveling by feeder bus. Based on the above analysis, the potential demand for a link to operate a feeder bus could be calculated as

$$
\begin{aligned}
& P d_{i j}=\frac{T d_{i j}}{S_{i j}} \times L_{i j} \times M_{i j} \\
& M_{i j}=1-a \times R_{i j} .
\end{aligned}
$$

$P d_{i j}$ is the potential demand if link $(i, j)$ operates a feeder bus line. $T d_{i j}$ is the aggregated traffic demand of link $(i, j)$. $S_{i j}$ is the average distance of passengers to be attracted to link $(i, j) . L_{i j}$ is the distance from the link to the rail transit station, assuming a linear distance between the midpoint of the link and the rail transit station. $M_{i j}$ is the potential demand reduction coefficient of the link. $R_{i j}$ is the number of operating conventional bus lines of the link. Finally, $a$ is the adjustment coefficient and can be obtained by investigations.

Before dividing the traffic zone, the travel situation that residents use near rail transit stations should be surveyed. Then, spatial cluster analysis can be employed to divide individuals with similar travel characteristics into the same traffic zone. To simplify the calculations, each grid is regarded as a traffic zone and the study area is treated by a gridding method, as shown in Figure 1. The following assumptions 

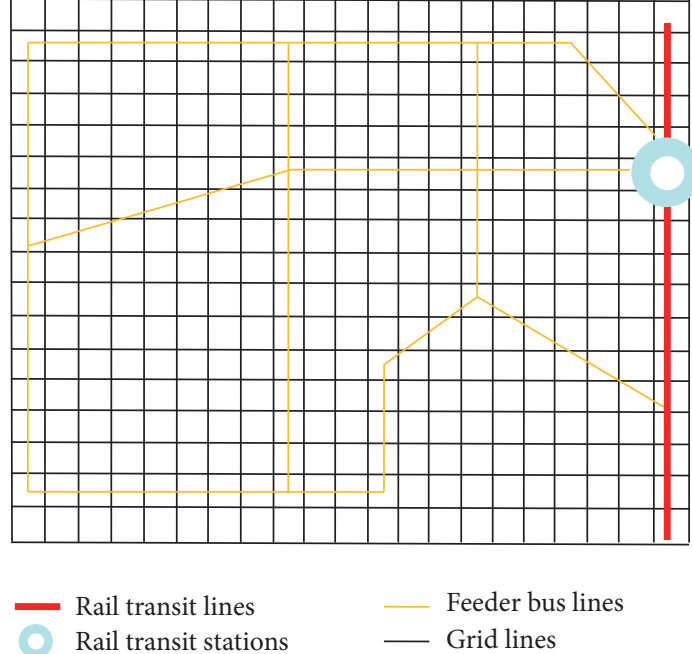

FIgURE 1: Schematic diagram of a gridding method.

are made: (1) assign passengers in the same grid to the same link, and passengers in different grids are assigned to different links, and (2) the shortest distance between the midpoint of each grid and the corresponding link is the distance between passengers inside that grid and the corresponding link.

Based on the assumptions, the logit model is employed to assign passengers inside each grid to a unique link; the distribution probability is shown in

$$
P_{k, i j}=\frac{e^{-S_{k, i j}}}{\sum_{(i, j) \in A} e^{-S_{k, i j}}} .
$$

$P_{k, i j}$ is the probability that grid $k$ is assigned to link $(i, j)$. $S_{k, i j}$ is the distance that passengers inside the grid match link $(i, j) . A$ is the set of all links in a regional area.

Therefore, based on (2), each grid is allocated to the links in the region, in accordance with a certain probability; then the attracted passenger flow of each link and corresponding average matching distance are calculated.

$$
\begin{aligned}
T d_{i j} & =\sum_{k \in U} T d_{i j} \times f(k, i j) \\
S_{i j} & =\frac{\sum_{k \in U} S_{k, i j} \times T d_{k} \times f(k, i j)}{T d_{i j}} .
\end{aligned}
$$

$T d_{k}$ is the passenger demand of grid $k . U$ is the set of all grids in a region. If grid $k$ is assigned to link $(i, j), f(i, j)=1$; otherwise $f(i, j)=0$.

Per the existing studies by Ceder [25], this paper assumes that $G=\{N, A\}$ indicates a set of links and nodes within a regional area. Each link $(i, j)$ corresponds to average travel time and potential demand indicators. Solving the model could generate a circular route starting and ending at a feeder rail transit station. The model maximizes the potential demand of passengers while complying with the constraint

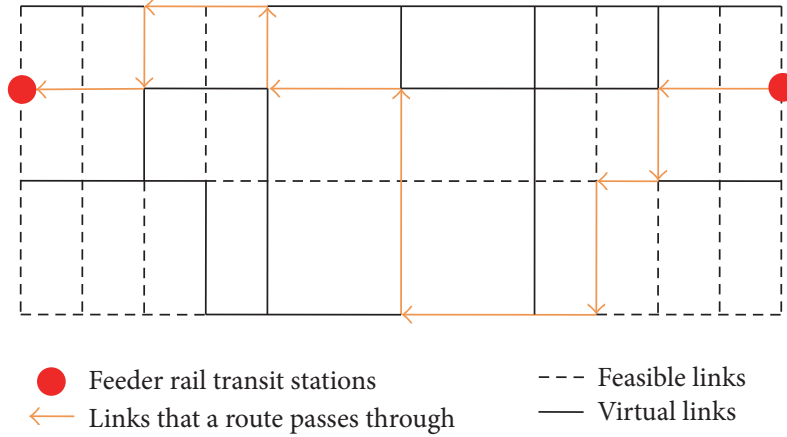

FIgURE 2: Schematic diagram of a road network topology.

of maximum circulating travel time $T$; the model can be calculated as follows:

$$
\begin{aligned}
\max & \sum_{(i, j) \in A} P d_{i j} \times x_{i j} \\
\text { Subject to: } & \sum_{(i, j) \in A} t_{i j} \times x_{i j} \leq T \\
& \sum_{m \in N} x_{i m}=\sum_{n \in N} x_{n i} \\
& \sum_{i \in N} x_{s i}=\sum_{i \in N} x_{i s} \\
& x_{i j} \in\{0,1\}, \quad \forall(i, j) \in A .
\end{aligned}
$$

Equation (5) represents the constraint of maximum travel time. Equations (6) and (7) are constraints of creating a new circular route in the road network. Equation (6) represents the number of links incoming to and outgoing from each node; the number of links in and out of each node is conserved [26]. Equation (7) represents that the route is closed. Equation (8) defines $x_{i j}$, where $x_{i j}=1$ indicates that link $(i, j)$ is part of the route; otherwise $x_{i j}=0$.

As the road network shows in Figure 2, the feeder bus can only travel routes via viable links. The regulations used are to generate a route from right to left and to classify and assign each node in accordance with different trends. All nodes in the road network are divided into eight types based on the alignment of links and assigned a value from 0 to 7 . The basic trend of a route is divided into up, left, or down and given a corresponding value of $1-3$, as shown in Table 1 . Therefore, the final route is a matrix consisting of the numbers 1,2 , and 3 .

The method described in Table 1 can express and generate any route under the condition of a given topology network. Before applying a genetic algorithm to solve the route problem, we should make the actual road network topology into a simple road network composed of several horizontal and vertical lines. Then, we make the topological network axissymmetric based on the left boundary and generate a route from right to left.

3.3. Solution Algorithm. The proposed model is essentially a route design problem in the field of operations research, which is an NP-hard problem that can be solved using some 
TABLE 1: Assignment of nodes and trend.

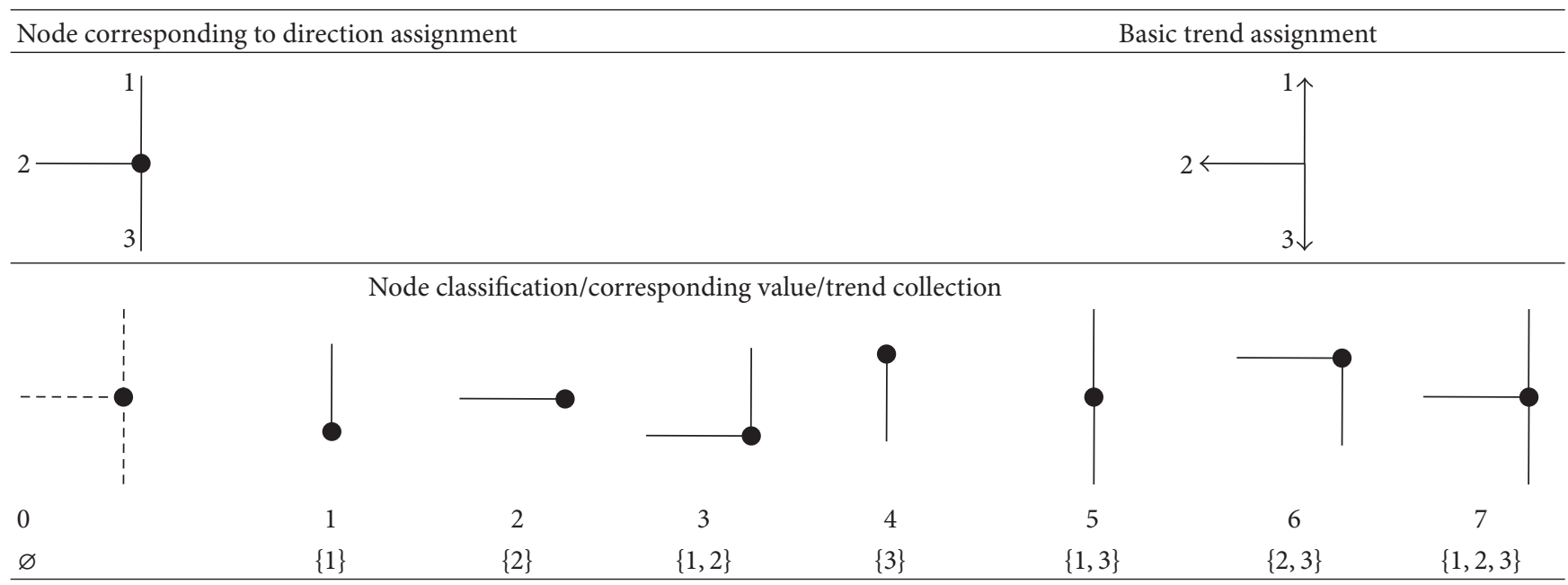

TABLE 2: Regional area and travel demand.

\begin{tabular}{lccccc}
\hline Area ID & 101 & 102 & 103 & 104 & 105 \\
\hline $\begin{array}{l}\text { Area }\left(\mathrm{km}^{2}\right) \\
\begin{array}{l}\text { Rail passenger } \\
\text { demand }\end{array}\end{array}$ & 1.78 & 1.97 & 1.79 & 2.09 & 3.53 \\
\begin{tabular}{l} 
(person/day) \\
\hline
\end{tabular} & 1236 & 1285 & 1620 & 1978 & 2451 \\
\hline
\end{tabular}

intelligent heuristic algorithms [27, 28]. Thus, per the existing studies by Goldberg [29], Chambers [30], and Liu and Meng [31], a genetic algorithm is employed to solve the model. Per the existing studies by Fang et al. in road traffic route searching, a depth-first search algorithm is advantageous for calculating the best route and getting multiple alternative optimal routes; this method is used to prove that genetic algorithms are feasible [32].

\section{Case Study}

This paper selects the Wei-Fang community of Shanghai as a test area. Metro line 6 passes through the region, and the Pudian station is set up as a transferring station because it is located in the city center of Shanghai. Sample surveys were conducted in the test area to get Origin-Destination data between numbered areas and the Pudian station for a given day. The Wei-Fang community was divided into five small areas, as shown in Table 2. The regional area was divided into grids using a method of regional grids; each grid cell represented a traffic zone of $100 \mathrm{~m} \times 100 \mathrm{~m}$.

The passenger flow density of each of the areas 101 to 105 is assumed to be consistent. Combining the data in Table 3 with (2), the passenger demand, the link matching situation of each grid, and the distances from each grid to the matching links could be calculated. Then, given the $12 \mathrm{~km} / \mathrm{h}$ speed of the feeder bus, the average traveling time could also be calculated. Per the survey of bus stations and line distribution, adjustment factor $a$ is calibrated to the value of 0.05 ; then $R_{i j}$ and $M_{i j}$ could be calculated. Relevant data are shown in Table 3;

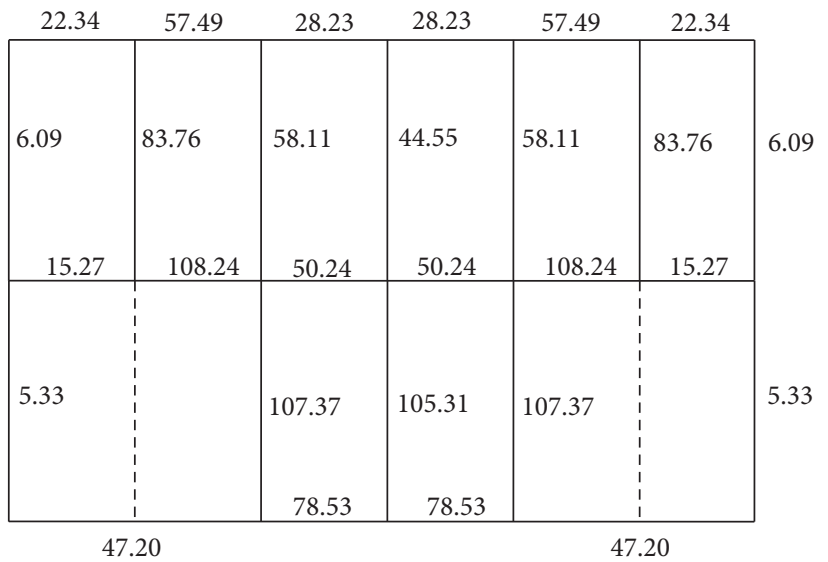

FIGURE 3: Network topology and link potential passenger demand by symmetry operations.

assuming that $P d_{i j}=P d_{j i}$, Table 3 records only the index value of each one-way link.

Based on the actual road network of the Wei-Fang community, the road network topology was established and symmetry operations were applied; potential passenger demand data were then loaded into the corresponding links, as shown in Figure 3. MATLAB software was used to program and solve the mathematical model. Setting the maximum traveling time to $T=75 \mathrm{~min}$, the iterative curve of link potential passenger demand could be obtained, as shown in Figure 4.

Figure 4 shows that, after inheriting to the eighth generation, the objective function is stable and the maximum number of potential passengers is 761. Additionally, a corresponding optimal route matrix is obtained. Reverting the topological route to the actual road network, the optimal route is obtained. To prove the accuracy of the genetic algorithm solutions, a depth first search algorithm is used to traverse all possible links under the topology network. The results obtained by genetic algorithms and depth first search algorithms are equal, and the corresponding route is the same. Therefore, 
TABLE 3: Relevant data of each link.

\begin{tabular}{|c|c|c|c|c|c|c|c|c|}
\hline Link & Link length $(\mathrm{m})$ & Average traveling time (min) & $T d_{i j}$ & $S_{i j}$ & $L_{i j}$ & $R_{i j}$ & $M_{i j}$ & $P d_{i j}$ \\
\hline$(1,2)$ & 570 & 2.85 & 296 & 4.02 & 1.1 & 9 & 0.55 & 44.55 \\
\hline$(2,3)$ & 506 & 2.53 & 551 & 5.18 & 0.99 & 0 & 1 & 105.31 \\
\hline$(4,5)$ & 595 & 2.98 & 819 & 3.31 & 0.71 & 2 & 0.9 & 158.11 \\
\hline$(5,6)$ & 508 & 2.54 & 1072 & 6.20 & 0.69 & 2 & 0.9 & 107.37 \\
\hline$(7,8)$ & 606 & 3.03 & 957 & 4.73 & 0.46 & 2 & 0.9 & 83.76 \\
\hline$(9,10)$ & 605 & 3.03 & 545 & 8.05 & 0.36 & 15 & 0.25 & 6.09 \\
\hline$(10,11)$ & 691 & 3.46 & 707 & 7.16 & 0.27 & 16 & 0.2 & 5.33 \\
\hline$(1,4)$ & 240 & 1.20 & 166 & 4.41 & 1.0 & 5 & 0.75 & 28.23 \\
\hline$(4,7)$ & 372 & 1.86 & 253 & 3.03 & 0.81 & 3 & 0.85 & 57.49 \\
\hline$(7,9)$ & 285 & 1.43 & 257 & 6.65 & 0.68 & 3 & 0.85 & 22.34 \\
\hline$(2,5)$ & 371 & 1.86 & 664 & 7.93 & 0.80 & 5 & 0.75 & 50.24 \\
\hline$(5,8)$ & 316 & 1.58 & 538 & 2.28 & 0.46 & 0 & 1 & 108.54 \\
\hline$(8,10)$ & 303 & 1.52 & 583 & 4.01 & 0.15 & 6 & 0.7 & 15.27 \\
\hline$(3,6)$ & 429 & 2.15 & 468 & 5.90 & 1.1 & 2 & 0.9 & 78.53 \\
\hline$(6,11)$ & 579 & 2.90 & 592 & 8.34 & 0.70 & 1 & 0.95 & 47.20 \\
\hline
\end{tabular}

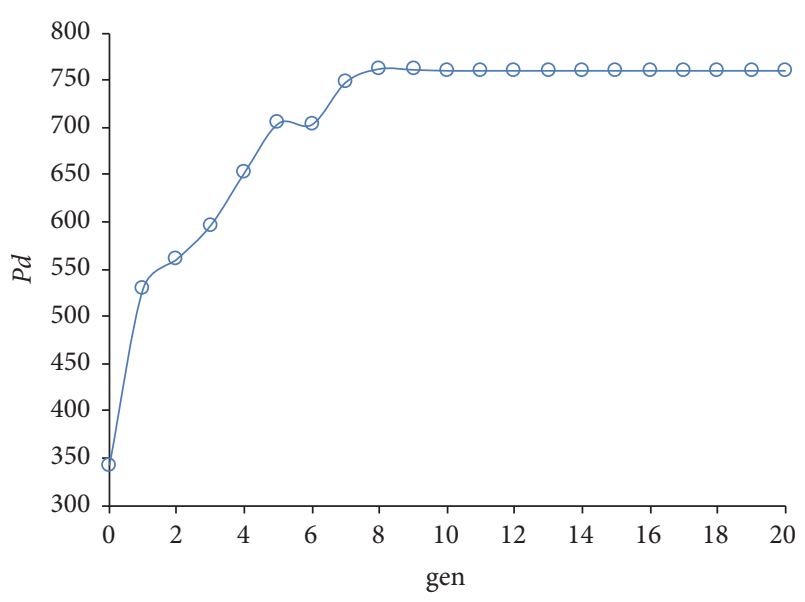

FIGURE 4: Iterative curve of link potential passenger demand.

it is considered that genetic algorithms obtain the optimal solution in this case. Per Table 3, the optimal route is calculated to be 5.6 kilometers and conforms to the functional orientation of short-distance travel and feeder service of a feeder bus; the route trend basically covers the links where conventional bus lines are fewer.

\section{Conclusions}

This paper studied urban road links and defined the potential demand that link open feeder bus services. Based on a circular route model, an optimal route starting and ending at the rail transit station was generated by genetic algorithm. As a case study, the Wei-Fang community of Shanghai was selected to verify the model validity. However, the definition of the study area and relationship with conventional bus line coverage is mainly determined by the Shanghai survey data. Multiple data should be collected to make comparison studies between cities in the future. The survey results of feeder bus lines in
Shanghai showed that cost is not a significant factor, and the model did not consider cost; distance, time, and cost should be considered together in the following studies. Furthermore, with the development of rail transportation networks, there are many rail transit stations surrounded by large residential communities; the service scope of rail transit stations will not only serve residential areas that are located on one side of rail transit lines. Therefore, in addition to singlecirculation feeder mode, overlap-circulation and round-trip feeder modes should be thoroughly studied.

\section{Competing Interests}

The authors declare that they have no competing interests.

\section{References}

[1] G. David, Community Transport: Policy, Planning, Practice, Gordon and Breach Press, Amsterdam, The Netherlands, 1995.

[2] R. B. Dial, "Transit pathfinder algorithm," Highway Research Record, vol. 205, pp. 67-85, 1967.

[3] F. Le Clercq, "A Public transport assignment method," Traffic Engineering and Control, vol. 14, no. 2, pp. 91-96, 1972.

[4] C. Chriqui and P. Robillard, "Common bus lines," Transportation Science, vol. 9, no. 2, pp. 115-121, 1975.

[5] S. Nguyen and S. Pallottino, "Equilibrium traffic assignment for large scale transit networks," European Journal of Operational Research, vol. 37, no. 2, pp. 176-186, 1988.

[6] M. D. Hickman and D. H. Bernstein, "Transit service and path choice models in stochastic and time-dependent networks," Transportation Science, vol. 31, no. 2, pp. 129-146, 1997.

[7] F. Kurauchi, M. G. H. Bell, and J.-D. Schmöcker, "Capacity constrained transit assignment with common lines," Journal of Mathematical Modelling and Algorithms, vol. 2, no. 4, pp. 309327, 2003.

[8] G. K. Kuah and J. Perl, "A methodology for feeder-bus network design," Journal of the Transportation Research Record, vol. 1120, pp. 40-51, 1987. 
[9] S. K. Chang and P. M. Schonfeld, "Multiple period optimization of bus transit systems," Transportation Research Part B, vol. 25, no. 6, pp. 453-478, 1991.

[10] S. Chien and P. Schonfeld, "Optimization of grid transit system in heterogeneous urban environment," Journal of Transportation Engineering, vol. 123, no. 1, pp. 28-35, 1997.

[11] S. I. Chien, L. N. Spasovic, and S. S. Elefsiniotis, "Evaluation of feeder bus systems with probabilistictime-varying demands and non-additive time Costs," Journal of the Transportation Research Record, vol. 1760, pp. 47-55, 2001.

[12] S. I.-J. Chien, "Optimization of headway, vehicle size and route choice for minimum cost feeder service," Transportation Planning and Technology, vol. 28, no. 5, pp. 359-380, 2005.

[13] S. Chien, Z. Yang, and E. Hou, "Genetic algorithm approach for transit route planning and design," Journal of Transportation Engineering, vol. 127, no. 3, pp. 200-207, 2001.

[14] A. Ceder, "Stepwise multi-criteria and multi-strategy design of public transit shuttles," Journal of Multi-Criteria Decision Analysis, vol. 16, no. 1-2, pp. 21-38, 2009.

[15] S. Jerby and A. Ceder, "Optimal routing design for shuttle bus service," Journal of the Transportation Research Record, vol. 1971, no. 1, pp. 14-22, 2006.

[16] W. Fan and R. B. Machemehl, "Optimal transit route network design problem with variable transit demand: genetic algorithm approach," Journal of Transportation Engineering, vol. 132, no. 1, pp. 40-51, 2006.

[17] D. O'Sullivan, A. Morrison, and J. Shearer, "Using desktop GIS for the investigation of accessibility by public transport: an isochrone approach," International Journal of Geographical Information Science, vol. 14, no. 1, pp. 85-104, 2000.

[18] S. N. Kuan, H. L. Ong, and K. M. Ng, "Solving the feeder bus network design problem by genetic algorithms and ant colony optimization," Advances in Engineering Software, vol. 37, no. 6, pp. 351-359, 2006.

[19] S. K. Chang and W. J. Yu, "Comparison of subsidized fixed and flexible-route bus systems," Journal of the Transportation Research Record, vol. 1557, no. 1, pp. 15-20, 1996.

[20] P. Shrivastav and S. L. Dhingra, "Development of feeder routes for Suburban railway stations using heuristic approach," Journal of Transportation Engineering, vol. 127, no. 4, pp. 334-341, 2001.

[21] W. Y. Szeto and Y. Wu, "A simultaneous bus route design and frequency setting problem for Tin Shui Wai, Hong Kong," European Journal of Operational Research, vol. 209, no. 2, pp. 141-155, 2011.

[22] J. Xiong, W. Guan, L. Song, A. Huang, and C. Shao, "Optimal routing design of a community shuttle for metro stations," Journal of Transportation Engineering, vol. 139, no. 12, pp. 12111223, 2013.

[23] J.-J. Lin and H.-I. Wong, "Optimization of a feeder-bus route design by using a multiobjective programming approach," Transportation Planning and Technology, vol. 37, no. 5, pp. 430449, 2014.

[24] J. R. Wu, Y. Zheng, and X. H. Chen, "Approaches to planning of subway station transfer facility in urban areas," Journal of Tongji University(Natural Science), vol. 36, no. 11, pp. 1501-1506, 2008.

[25] A. Ceder, Public Transit Planning and Operation: Theory, Modeling and Practice, Elsevier Press, Burlington, UK, 2007.

[26] H. A. Eiselt, M. Gendreau, and G. Laporte, "Link routing problems, part I: the Chinese postman problem," Operation Research, vol. 43, pp. 231-242, 1995.
[27] X. H. Jiang, X. C. Guo, and B. Ran, "Optimization model for headway of a suburban bus route," Mathematical Problems in Engineering, vol. 2014, Article ID 979062, 6 pages, 2014.

[28] C. L. Martins and M. V. Pato, "Search strategies for the feeder bus network design problem," European Journal of Operational Research, vol. 106, no. 2-3, pp. 425-440, 1998.

[29] E. D. Goldberg, Genetic Algorithms in Search Optimization and Machine Learning, Addison-Wesley, Reading, Mass, USA, 1989.

[30] L. Chambers, Practical Handbook of Genetic Algorithms: Applications, CRC Press, Boca Raton, Fla, USA, 1995.

[31] Z. Liu and Q. Meng, "Distributed computing approaches for large-scale probit-based stochastic user equilibrium problems," Journal of Advanced Transportation, vol. 47, no. 6, pp. 553-571, 2013.

[32] J. Fang, Z.-H. Du, F. Zhang, Z. Zeng, and R.-Y. Liu, "Heuristic depth-first directional algorithm for shortest path searching in traffic networks," Journal of Zhejiang University(Science Edition), vol. 40, no. 4, pp. 469-474, 2013. 


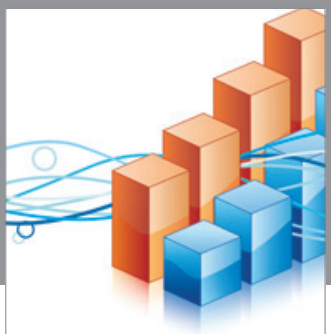

Advances in

Operations Research

vatem alat4

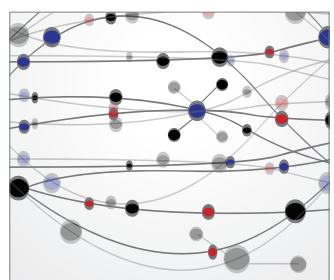

\section{The Scientific} World Journal
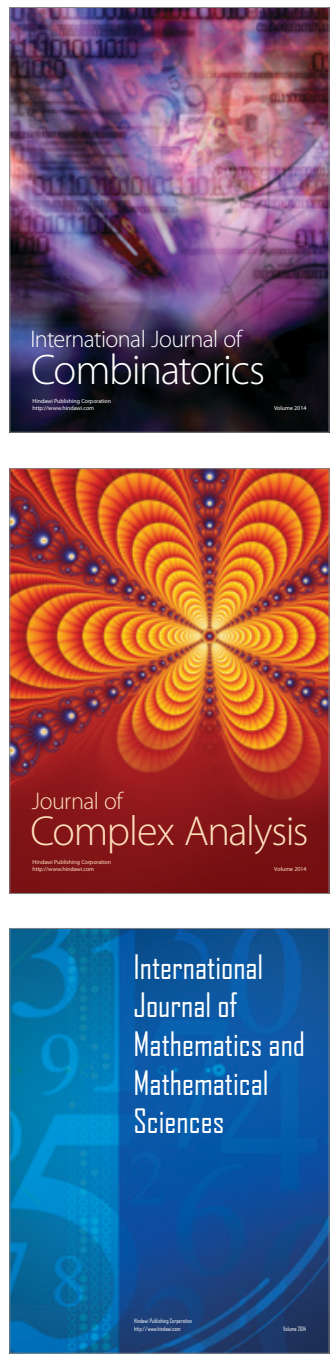
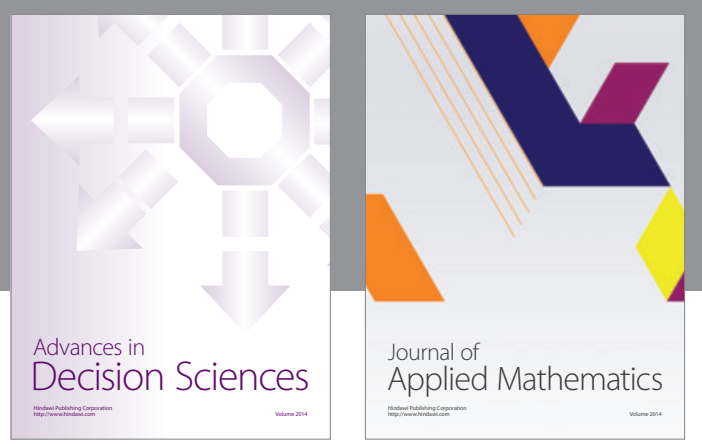

Algebra

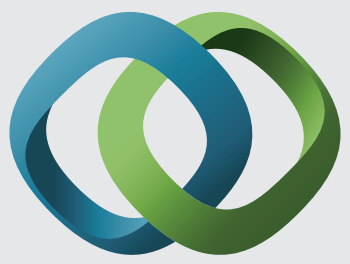

\section{Hindawi}

Submit your manuscripts at

https://www.hindawi.com
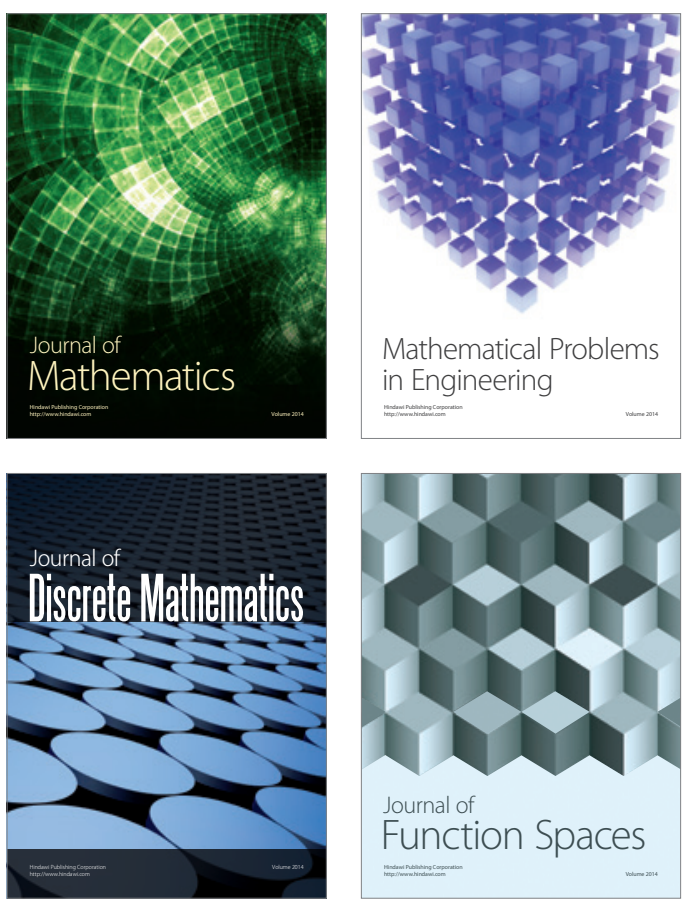

Mathematical Problems in Engineering
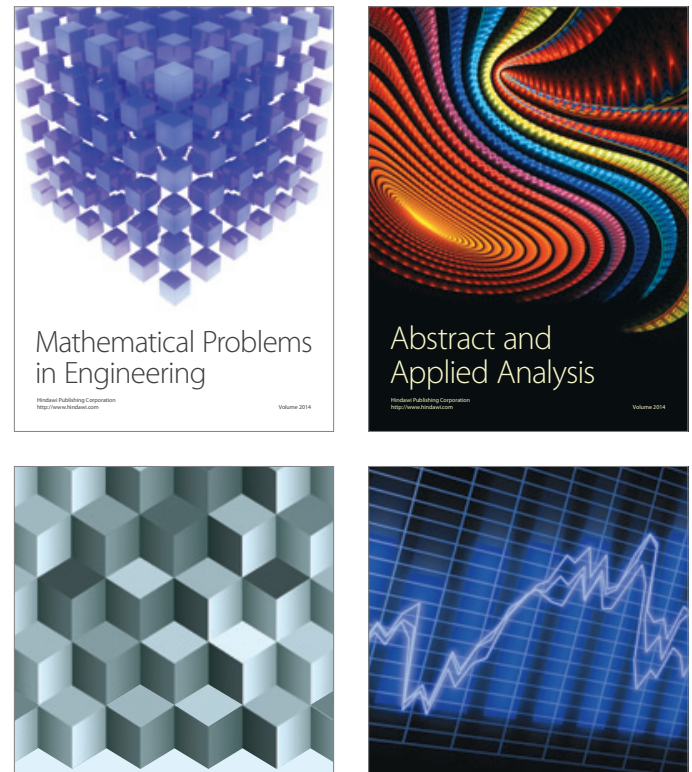

Journal of

Function Spaces

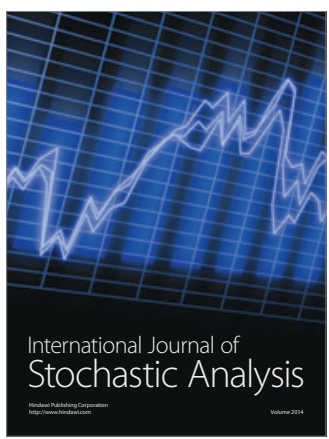

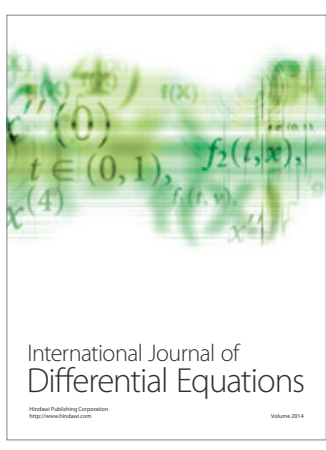
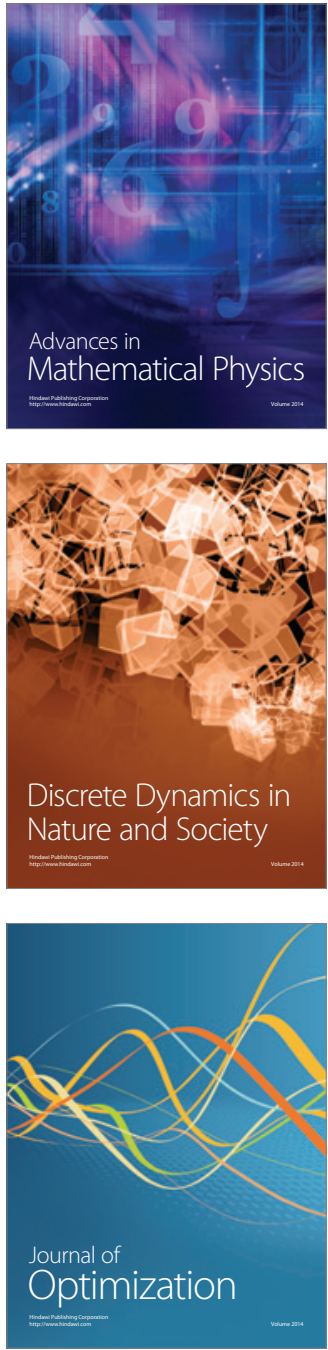